Año: 2020

Fecha de aceptado: $13 / 2 / 2020$

Correo: revista.societas@up.ac.pa

Numero: 2 Número de Páginas: 1-24

URL:https://revistas.up.ac.pa/index.php/societas

\title{
PANORAMAS ACTUALES DE LA DIDÁCTICA DE LA LITERATURA EN COLOMBIA: OPORTUNIDADES Y RETOS EN LA EDUCACIÓN BÁSICA SECUNDARIA Y MEDIA*
}

\section{CURRENT OVERVIEWS OF DIDACTICS OF LITERATURE IN COLOMBIA: OPPORTUNITIES AND CHALLENGES IN BASIC EDUCATION SECONDARY AND MIDDLE}

\author{
Stefany Carrillo García** \\ https://orcid.org/0000-0001-7861-9135 \\ Javier Zúñiga* $^{*}$ \\ jzunigac@yahoo.com
}

Universidad Metropolitana de Educación Ciencia y Tecnología. Doctorado en Ciencias de la Educación. Facultad de Educación. Panamá, Panamá

\section{Resumen}

En este artículo se recopilan, analizan e interpretan fuentes bibliográficas académicas para actualizar e identificar cómo se concibe y se desarrolla la didáctica de literatura en la educación básica secundaria y media en Colombia. Se presentan los resultados de la investigación teórico-descriptiva de tipo documental que corresponde a la sistematización de documentos sobre la didáctica de la literatura en Colombia publicados en los últimos cinco años (2015-2020) en bases de datos como SCOPUS, Google Académico y Dialnet.

Entre los principales hallazgos se evidencia que la didáctica de la literatura sigue inmersa dentro de la didáctica de la lengua materna, que aunque tiene un nicho en común provoca que la enseñanza de la literatura propiamente dicha se releve y se le otorgue una función mediadora en el desarrollo de otras competencias (comprensión de lectura, producción escrita, gramática, sintaxis, oralidad, etc.) y de otras disciplinas (como la historia, la geografía, etc.). Se concluye consolidando el rol educativo de la literatura como hacedora de identidades universales y culturales; un arte que enriquece los aspectos humanos y su capacidad creativa, estética, analítica, crítica, innovadora y de sensibilización.

Palabras clave: Didáctica, Literatura, Enseñanza, Secundaria, Colombia.

\footnotetext{
${ }^{* *}$ Doctoranda en Educación con énfasis en Investigación y Formulación de Proyectos Educativos, Universidad de Educación, Ciencia y Tecnología en Panamá- UMECIT. Magíster en Semiótica. Licenciada en Español y Literatura. Correo electrónico: stcanfor36@hotmail.com

*** Doctor en Ciencias Sociales, mención Educación, FLACSO - Buenos Aires, Argentina. Correo electrónico: jzunigac@yahoo.com
} 


\section{Summary}

In this article, bibliographic sources are compiled, analyzed and interpreted to update and identify how the didactics of literature in high school in Colombia is conceived and developed. The results of the theoretical-descriptive documentary research that correspond to the systematization of documents on the didactics of literature in Colombia and that have been published in the last five years (2015-2020) in databases such as SCOPUS, Academic Google and Dialnet.

As main findings, it is evident that the didactics of literature continues to be immersed within the didactics of the language. Although these have a niche in common, this situation causes the teaching of literature (itself) to be relieved and given a mediating function in the development of other competences (reading comprehension, written production, grammar, syntax, orality, etc.) and other disciplines (such as history, geography, etc.). In conclusion, the educational role of literature as a maker of universal and cultural identities; an art that enriches the human aspects and their creative, aesthetic, analytical, critical, innovative and awareness-raising capacity.

Keywords: Didactics, Literature, Teaching, Secondary, Colombia

\section{Introducción}

La siguiente sistematización de documentos pretende dar un panorama de los supuestos, los avances y las tendencias de desarrollo en el campo de la didáctica de la literatura en Colombia entre 2015 y 2010. Se analizaron fuentes documentales seleccionadas a partir de su relevancia y validez científica y académica (tesis de pregrado, posgrado, artículos de investigación, reflexión, revisión, ensayos, entre otros). Este propósito surge del trabajo de tesis doctoral que está adscrito al grupo "Investigación, evaluación y formulación de proyectos educativos" de la Universidad Metropolitana de Educación, Ciencia y Tecnología-UMECIT, a partir de su línea de investigación "Currículum y didáctica".

La actualización conceptual de los maestros con respecto a los modelos y teorías de la literatura es imprescindible para diseñar, rediseñar sus métodos de enseñanza que orienten y promuevan el aprendizaje así como la sensibilidad artística de la literatura.

Visto así, este campo de estudio es complejo de definir y dirigir para dar cumplimiento al objetivo de desarrollar al lector la experticia para interpretar textos, construir el significado simbólico de los mismos y articularlos con todos los campos del saber. No obstante, estas complejidades del estudio de la didáctica de la literatura prometen hallazgos fructíferos con respecto al permanente diálogo entre las diferentes concepciones de la misma.

\section{Metodología}

La Investigación se enmarca en las Ciencias Humanas, en concreto en el mundo de la literatura, sus procesos didácticos y prácticas educativas. La metodología es de tipo cualitativo, descriptivo, y de revisión documental que consiste en rastrear, organizar y sistematizar un conjunto de fuentes bibliográficas que profundizan en el conocimiento teórico-práctico de la literatura y su didáctica en el contexto de la educación secundaria y 
media en Colombia. De acuerdo con la tesis doctoral que se está adelantando y que tiene como título: "Análisis de las estrategias didácticas de la literatura en los profesores de bachillerato del área metropolitana de Bucaramanga", se construyó un marco teórico que configuró las bases epistémicas y discursivas que profundizan en el tema. La búsqueda de la documentación fue dirigida bajo los criterios de exploración con las palabras clave "Didáctica", "Literatura", "Enseñanza", "Secundaria", "Colombia" en las base de datos SCOPUS y en los buscadores de artículos científicos Google Académico y DIALNET entre mayo 2019 y septiembre de 2020.

Una vez realizado el rastreo de 70 documentos se organizaron identificando el título, el autor, el año de publicación, la metodología utilizada, los resultados y conclusiones de cada estudio. Posteriormente, se diseñaron matrices de sistematización de las tres fuentes de información seleccionadas. A partir de aquí, se procedió a analizar globalmente los entramados de sentido común y diferencias entre los documentos para generar conclusiones sobre el rol de la literatura en la educación, la importancia del estudio de la didáctica de la literatura y la necesidad de la actualización conceptual en este ámbito.

\section{Contextualización Políticas Educativas colombianas actuales con relación a la Literatura}

La política educativa colombiana se rige por la Constitución Política de 1991 y la Ley General de Educación 115 de 1994; en estas se ha configurado el modelo de ciudadano que se quiere formar, de acuerdo a los deberes y derechos que se le atribuye. Fundamentalmente, la legislación y política administrativa del país establecen la educación y su acceso como un derecho primordial de las personas, por tanto, expresan su compromiso y responsabilidad para garantizar una formación de calidad, garantizado la cobertura y acceso a los servicios educativos en todos los sectores del país. En la normatividad se manifiesta una política progresiva, que permite el desarrollo individual y colectivo en pro de la sociedad, sus realidades y transformaciones.

La Ley General de Educación 115 de 1994 determina el área del lenguaje y comunicación como componentes fundamentales para la formación de los estudiantes en todos los grados y niveles de formación, como también señala la importancia de perfilar una actitud crítica frente a la información que circula. En concreto, sobre la literatura en educación secundaria y media, se encuentra:

Artículo 22. Objetivos específicos de la educación básica en el ciclo de secundaria. Los cuatro (4) grados subsiguientes de la educación básica que constituyen el ciclo de secundaria, tendrán como objetivos específicos los siguientes:

a) El desarrollo de la capacidad para comprender textos y expresar correctamente mensajes complejos, orales y escritos en lengua castellana, así como para entender, mediante un estudio sistemático, los diferentes elementos constitutivos de la lengua;

b) La valoración y utilización de la lengua castellana como medio de expresión literaria y el estudio de la creación literaria en el país y en el mundo; [...]

n) La utilización con sentido crítico de los distintos contenidos y formas de información y la búsqueda de nuevos conocimientos con su propio esfuerzo [...] 
Visto esto, para el Estado el estudio de la lengua materna y la literatura están relacionadas con las capacidades lectoras, de producción escrita, pensamiento crítico y expresiones creativas que puede formarse en los estudiantes. No hay un parágrafo que esté enfocado netamente a la función social, estética, identitaria y de sensibilización de la literatura, pareciera que desde estos componentes, la literatura es solo un producto para ser estudiado desde ámbitos del uso de la lengua y desde una mirada histórica nacional y mundial.

Con respecto a otras normativas para el área de lenguaje y Literatura, se encuentran los Lineamientos curriculares del área de la lengua Castellana del Ministerio de Educación Nacional, MEN (1998) en el que se establecen unas pautas orientativas sobre diferentes enfoques teóricos y prácticos en cuanto al desarrollo de competencias comunicativas en la lengua materna y la literatura.

Aunque es evidente el impacto de las orientaciones curriculares y pedagógicas ante el interés por cumplir índices y estándares evaluativos, como también son claros los valiosos aportes interdisciplinares para el estudio de la lengua y el lenguaje, no hay claridad de cómo estos aportan al estudio de la literatura. Solo se está ofrecen generalidades o una perspectiva estructural a la literatura, omitiendo aportes teóricos de la recepción, estudios de la identidad, de la estética, análisis del discurso, semiótica cultural, semiótica pasional, entre otros.

Asimismo, el Ministerio de Educación Nacional, en 2015, elaboró los Derechos Básicos de Aprendizaje (DBA), los cuales determinan aquellos conocimientos, habilidades y actitudes que, se supone, debe desarrollar el estudiante en cada grado y área particular; estos se configuran atendiendo una relación coherente con los Lineamientos Curriculares y los Estándares Básico de Competencias (EBC).

En el caso del área de lenguaje en bachillerato $\left(6^{\circ}-11^{\circ}\right)$, los DBA relacionados con el componente literario son los indicadores 3 y 4 de cada grado, los cuales son:

\section{Tabla 1. Los DBA del componente literario en educación secundaria y media}

\section{Grado $6^{\circ}$}

3. Reconoce las obras literarias como una posibilidad de circulación del conocimiento y de desarrollo de su imaginación.

4. Identifica algunas expresiones de diferentes regiones y contextos en las obras literarias. (MEN, 2015, p.29)

Grado $8^{\circ}$

3. Reconoce en las producciones literarias como cuentos, relatos cortos, fábulas y novelas, aspectos referidos a la estructura formal del género y a la identidad cultural que recrea.

4. Comprende que el género lírico es una construcción mediada por la musicalidad, la rima y el uso de figuras retóricas, que permiten recrear una idea, un sentimiento o una situación. (MEN, 2015, p.37)

\section{Grado $10^{\circ}$}

3. Caracteriza la literatura en un momento particular de la historia desde el acercamiento a sus principales exponentes, textos, temáticas y recursos estilísticos.

\section{Grado $7^{\circ}$}

3. Establece conexiones entre los elementos presentes en la literatura y los hechos históricos, culturales y sociales en los que se han producido.

4. Clasifica las producciones literarias a partir del análisis de su contenido y estructura en diferentes géneros literarios. (MEN, 2015, p.33)

\section{Grado $9^{\circ}$}

3. Analiza el lenguaje literario como una manifestación artística que permite crear ficciones y expresar pensamientos o emociones.

4. Compara los formatos de obras literarias y de producciones audiovisuales con el propósito de analizar elementos propios de la narración. (MEN, 2015, p.41)

\section{Grado $11^{\circ}$}

3. Determina los textos que desea leer y la manera en que abordará su comprensión, con base en sus experiencias de formación e inclinaciones literarias. 
4. Formula puntos de encuentro entre la literatura y las artes plásticas y visuales. (MEN, 2015, p.45)
4. Identifica, en las producciones literarias clásicas, diferentes temas que le permiten establecer comparaciones con las visiones de mundo de otras épocas. (MEN, 2015, p.49)

Fuente: MEN (2015, pp. 29, 33, 37, 41, 45 y 49)

Como se ve, la mayoría de verbos orientadores se centran en el plano de: identificar, determinar, caracterizar, establecer o clasificar, es decir, en las categorías cognitivas de recolección de información y comprender, teniendo en cuenta el dominio taxonómico cognitivo propuesto por Bloom y Krathwohl (1956). Para el MEN es irrelevante el desarrollo de las competencias (intra, inter) analíticas, evaluativas y argumentativas en las temáticas y componentes literarios, es decir, ¿cuál es el papel de la literatura para la perspectiva educativa estatal? ¿Para qué sirve la literatura? ¿Para qué se articula en los procesos de enseñanza? Pareciera que la literatura y sus autores son un requisito de conocimiento de cultura general e historia, pero desconoce su objetivo transformador, humanista, reflexivo, creador, innovador y de configuración identitaria de individuos y sociedades.

\section{La didáctica de la literatura en Colombia}

Antes de centrar la atención en la documentación actual, se considera pertinente resaltar cuatro estudios colombianos que entre el 2004-2013 sentaron las bases para el estudio de la didáctica de la literatura en Colombia y que en gran medida, han motivado el desarrollo de la investigación que enmarca este artículo, como también han sido citados numerosamente por otros estudiosos de la enseñanza de la literatura en los últimos años. Con miras a relacionar los aportes de estos autores, se relacionan:

Fabio Jurado Valencia del Departamento de Literatura Universidad Nacional de Colombia, en su artículo "Palimpsestos: la literatura en el contexto escolar" (2004) reflexiona sobre el papel del maestro de literatura en el desarrollo cultural y científico del país. Reconoce la problemática social, la desarticulación de las políticas del MEN con los nuevos enfoques de la didáctica de la literatura y se centra en reconocer que existe un desconocimiento sobre ¿Cómo enseñar la literatura? El investigador centra su atención en la necesidad de que los maestros articulen los intereses de los estudiantes a las propuestas literarias usadas en clase y muestra los resultados significativos que han tenido los profesores que han logrado promover la literatura desde otros ámbitos sociales o materiales según el contexto escolar.

El autor alude que es difícil para un maestro cumplir con lo que requieren los lineamientos curriculares y lo que realmente necesita un estudiante y que esa brecha es la que se necesita examinar. En este sentido, este artículo se remite a lo planteado por Jurado para justificar y empezar a considerar el análisis de estas situaciones entre lo teórico y la praxis del docente de formación secundaria y media.

Asimismo, las profesoras Zulma Martínez y Ángela Rocío Murillo Pineda de la Universidad Pedagógica Nacional de Bogotá, desarrollaron la investigación "Concepciones de la Didáctica de la Literatura en Colombia durante los últimos diez años" (2013). Registran la evolución de la didáctica de la literatura en el último decenio. De manera que, a través de su rastreo, se establece que las nociones de la enseñanza-aprendizaje de la literatura más relevantes se han centrado desde la dimensión estética y lúdica, la metodología de análisis literarios y una didáctica de la literatura desde los Géneros Literarios. El presente artículo de 
revisión posibilita actualizar el análisis de dichas tendencias didácticas entre los años 20152020, complementando así los enfoques y estrategias que hasta la fecha, orientan la práctica formativa.

Con respecto a la didáctica de la literatura en el bachillerato en Colombia resalta: "Lectura literaria en secundaria: la mediación de los docentes en la concreción de los repertorios lectores" (2013) de Mery Cruz Calvo. Se realiza un trabajo de campo con docentes de lengua y literatura de colegios de la ciudad de Cali, Colombia, en los niveles de educación Básica Secundaria y Educación Media, con el fin de investigar si sus prácticas pedagógicas dinamizan, contextualizan y potencializan los repertorios lectores de los estudiantes. Después de analizar los discursos de profesores y estudiantes, Cruz (2013) concluye que sí hay una mediación significativa entre el hacer docente y la formación literaria. Concluye que:

Hay mediaciones que están encaminadas a educar en la apreciación literaria a través de trabajos puntuales con las obras de ficción, y otras intervenciones docentes que se encaminan a un tipo de educación más de carácter cultural, donde la obra literaria es una más entre otros discursos que se trabaja para lograr este propósito. En cualquier caso, afirmamos que la mediación docente es definitiva en la concreción de los repertorios lectores, está intervención facilita que los jóvenes acepten leer un texto porque encuentran en ellos repertorios comunes. (p.333)

En Bucaramanga, Santander, se encuentra una investigación realizada por el grupo "Pedagogía y Lenguajes" de la Universidad Cooperativa de Colombia (Moreno et al., 2011), en "Cómo enseñar literatura en el aula, propuestas creativas para maestros activos". En este texto, se compilaron propuestas didácticas y pedagógicas para la enseñanza de la literatura en primaria y secundaria. Lo más significativo de estos trabajos es que reúnen y articulan enfoques teórico-prácticos de estudiosos del lenguaje y que pueden relacionarse con los procesos literarios, tales como: Daniel Cassany, Umberto Eco, Hans Gadamer, Michael Halliday, Roman Ingard, Wolfgang Iser, Ana María Kaufman, Jorge Larrosa y Jan Mukarovsky. Además de los anteriores se mencionan los autores colombianos: Mónica Bermúdez Grajales, Gloria Esperanza Bernal, Fabio Jurado Valencia, Mauricio Pérez Abril y Guillermo Zamudio Bustamante.

En este sentido, se estructura un manual para la enseñanza de la literatura que compila experiencias didácticas formativas dentro del aula de diversos licenciados en Humanidades y español. Si bien el libro no configura una teoría nueva sobre la didáctica de la literatura para el contexto y necesidades propiamente colombianas, sí plantea una propuesta colectiva de aplicación teórica a la praxis educativa.

\section{Resultados y discusión de la revisión documental 2015-2020}

Se aclara que la presentación secuencial de las categorías que corresponde a los resultados de la revisión documental no atañe a características evolutivas o cronológicas, pues todas ellas son prácticas didácticas de la literatura que se han develado como vigentes, coexistentes y hasta presentan hibridación entre ellas en el contexto educativo colombiano de la formación secundaria y media.

Así pues, se presenta la relación de categorías halladas con relación a las didácticas actuales de la literatura en el aula de clase colombiana contemporánea como los resultados y discusión en torno a ellas. 


\section{Figura 1. Categorías de los usos didácticos y pedagógicos de la Literatura en Colombia 2015-2020}

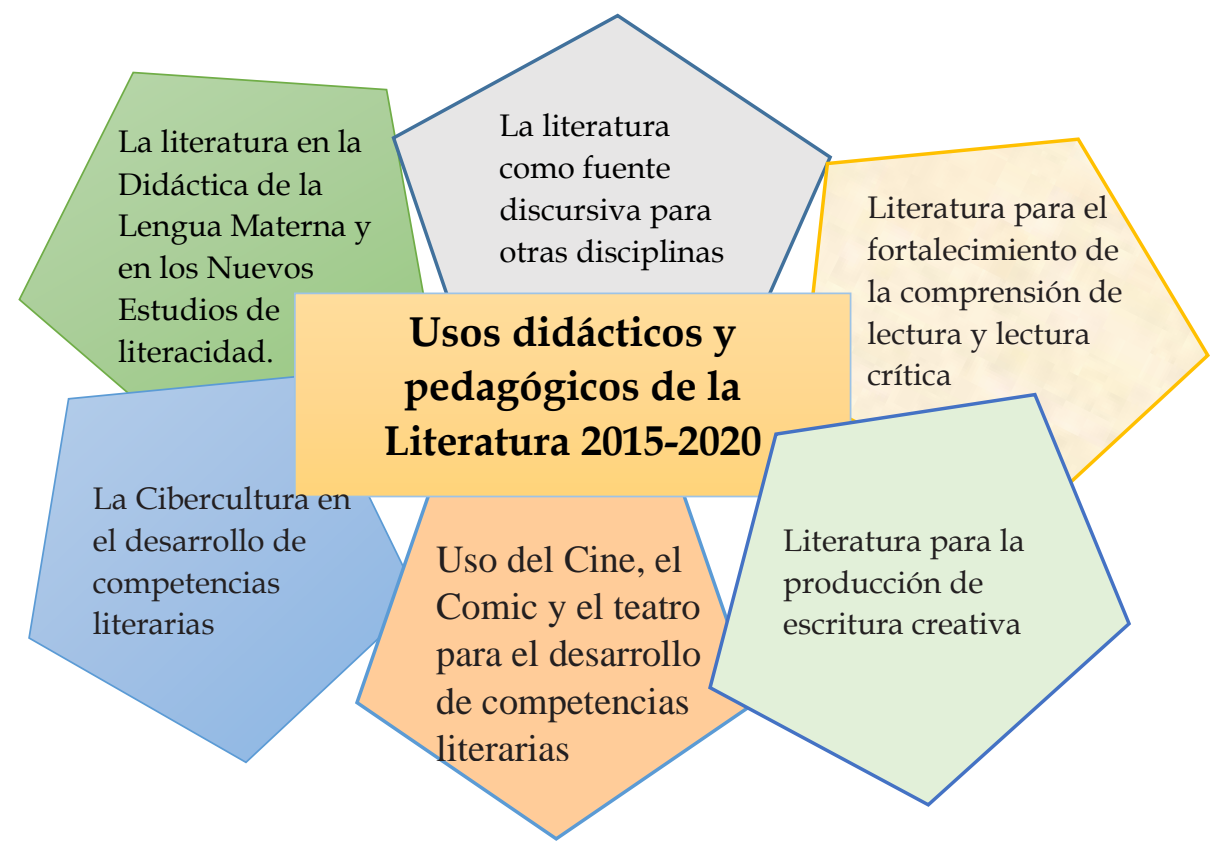

Fuente: Elaboración propia.

\section{Categoría: La literatura como fuente discursiva para otras disciplinas}

Las letras narrativas y líricas se retoman como fuentes sensibles de la percepción humana ante sus experiencias de vida, los espacios que lo rodean, los valores axiológicos en torno a las prácticas sociales y culturales que enmarcan épocas concretas, entre muchos otros aspectos que acogen la enseñanza de la literatura con relación a otras disciplinas o campos científicos. En los últimos años se han registrado diversas propuestas didácticas y pedagógicas para la enseñanza de la geografía y la historia usando la literatura como fuente de consulta, de análisis e interpretación.

Esto permite evidenciar que se intenta entretejer una educación interdisciplinar, una comprensión holística de la ciencia más allá de datos y registros cuantificadores en busca de una validez objetiva, una superación de la enseñanza del contenido a una enseñanza globalizadora de la lengua y la literatura en la educación secundaria, como ya proponía Álvarez (1991). Se está reconociendo en otros campos del saber la importancia del aspecto humano, de los procesos de significación que se configuran en los discursos literarios. Con esto, no se quiere entrar a discutir sobre la teoría de interpretación más adecuada para el análisis de los datos literarios, pero es claro que hay una tendencia e influencia de la semiótica discursiva, la semiótica de los objetos y la semiótica de las culturas. Por ejemplo, Alexánder Cely Rodríguez y Nubia Moreno Lache (2016) publicaron una compilación de propuestas interdisciplinares de la literatura en la enseñanza de la geografía, la cual rescata la función articuladora de los espacios, la ciudad, el campo y el paisaje en las letras literarias, y cómo estas pueden abrir interpretaciones y expresiones simbólicas y oníricas que posibilitan la recuperación memorística e histórica del territorio. 
Cely y Moreno (2016) retoman los nexos entre la geografía y la literatura que desde el siglo XX ya había expuesto Eric Dardel (1952) en su obra L'homme et la terre, que proponía superar la fragmentación entre geografía física y geografía humana para alcanzar la interpretación del espacio geográfico. Los autores proponen secuencias didácticas para enseñar la geografía, en concreto los espacios de la ciudad latinoamericana y bogotana con relación a los individuos que la co-habitan a partir del análisis de textos narrativos como: "El Aleph" de Jorge Luis Borges (1949), "Según la costumbre" de Gonzalo Mallarino Flórez (2003), "Los parientes de Ester" de Luis Fayad (1978) y "El ruido de las cosas al caer" de Juan Gabriel Vásquez (2011).

La relación de la literatura con otras disciplinas no es nueva, pero vale la pena resaltar la recuperación del reconocimiento de las voces narrativas como discursos humanísticos y válidos para la formación articuladora en la secundaria y media. La enseñanza de la literatura se consolida como una forma de expresión, representación, y de conocimiento ante diferentes emociones y pensamientos que se han vivido en el mundo. Devela una lectura subjetiva del ser humano, quien interpreta y percibe y valora sus entornos en múltiples lenguajes y desde los significados que adquieren para la persona. En el caso de la geografía, Dadón (2003) alude que "es convocada para ser metáfora de la literatura" (p. 9), de allí que percibir el espacio geográfico desde las letras literarias instaura la posibilidad de categorizar y analizar el espacio atendiendo no solo aspectos tipográficos, físicos o técnicos, sino también desde la mirada de los sentidos que también son dicientes de información significativa tanto en el ámbito investigativo.

Otro caso ilustrativo es el de la literatura para la enseñanza de la historia. Javier Jaramillo (2018) realiza una investigación donde propone la literatura como estrategia didáctica para la enseñanza de la historia en estudiantes de bachillerato, a partir del estudio de la violencia en Colombia en novelas históricas de Alba Lucia Ángel, Cecilia Caicedo Jurado y Ana María Jaramillo. Su objetivo fue estudiar, con los alumnos, los procesos históricos a través de lenguajes literarios más atractivos, significativos y dinámicos. El uso de la literatura en este tipo de trabajo intertextual e inter-dialógico entre los datos literarios y los datos históricos implica habilidades integradoras, analíticas y de reconstrucción de la información significativas dentro del proceso lector.

Enseñar desde una interdisciplinariedad histórica-literaria permite superar modelos de enseñanza que se limitan a abordajes teóricos, positivistas, de registros monumentales que poco puede relacionar el estudiante con hechos que en realidad han sido ajenos para él o que no son parte de su cotidianidad. Por tanto, el uso didáctico de la literatura para la enseñanza de la historia permite que el estudiante se aproxime a voces narrativas que en medio de sus vivencias personificadas expresen no solo fechas o sucesos, sino que desarrollen la dimensión humana, esa existencia que sufre, se angustia, siente contrariedad, temor, entre otras emociones que se dan en el marco de una trama novelística ambientada en un contexto histórico particular, que dan cuenta de situaciones sociales, políticas, culturales, religiosas que han marcado hitos que ameritan criticar, reflexionar.

Se logra llevar procesos de enseñanza inter-analítica con los estudiantes, donde la literatura tiene una función informativa-discursiva enriquecedora. Si bien existen múltiples investigaciones interpretativas que articulan la literatura con la geografía, la historia y la filosofía, estas se han desarrollado en el marco de la Educación Superior y en líneas de investigación de las prácticas sociales, culturales y antropológicas, por tanto es significativo que los docentes logren transformar los metalenguajes investigativos y científicos de su 
disciplina y los adapten didácticamente al aula de clase de bachillerato, que apuesten por una formación globalizada, comprensiva, crítica y argumentativa.

El uso de la literatura como fuente discursiva permite acercarse a diversos paradigmas que caracterizaron educación clásica de la enseñanza humanística, se comprende la obra como una interpretación de la realidad, una configuración subjetiva humana que se incorpora para el conocimiento y el estudio de la evolución del pensamiento individual y social, de los espacios humanos, de la temporalidad socio-histórica. Coexiste una urgente necesidad para repensar las estrategias didácticas para enseñar la historia y la geografía; construir perspectivas formativas alternativas e innovadoras y para esto la literatura juega un papel importante por su función simbólica, integradora de lenguajes, representativa y referencial, que permite al estudiante no solo conocer sentencias, nombres, datos, registros $o$ conocimientos físicos y técnicos, sino trasladarlo al mundo vivencial de los personajes.

\section{Categoría: La literatura en los procesos de lectura}

Según la Encuesta Nacional de Lectura-ENLEC (Consumo Cultural del DANE 2017) “el número de libros leídos al año por los colombianos que sí leen es de 5,1, mientras que el de la población total (que incluye los no lectores) es de 2,7 libros al año". Surgen las preguntas: ¿Qué metodologías educativas, formativas y sociales se han implementado en el aula de clase para el desarrollo de un hábito lector en la nación? ¿Cuáles factores sociales, culturales y educativos inciden en la formación literaria? Aunque son varios los sujetos y circunstancias que pueden influenciar o afectar la cultura lectora (familia, amigos, redes sociales, medios de comunicación, políticas de difusión informativa nacional, espacios culturales de la zona de vivienda, entre otros), es una realidad que en Colombia, desde sus políticas de cobertura educativa, la mayoría de sus ciudadanos han asistido a un aula de clase, donde han invertido tiempo en actividades formativas. En este sentido, es innegable la importancia de las instituciones educativas, como espacios de influencia para la formación lectora y literaria.

Hablar de la enseñanza de la lectura y sus procesos implica cuestionarse ¿Qué tipos de lecturas se fomentan en el aula? ¿Qué géneros o tipos de texto? ¿Con qué fin? No es nueva la reflexión del impacto que el modelo de competencias, promovido por la OCDE, ha tenido en los criterios de selección de qué se enseña. Como se mostró en apartados anteriores, en estos momentos los maestros colombianos se ven inmersos en una variedad de exigencias que les demandan orientar sus prácticas educativas en el cumplimiento de requerimientos: lineamientos curriculares estatales, Derechos básicos de aprendizaje (DBA), los planes individuales de ajustes razonables (PIAR), los Diseños Universales de Aprendizaje (DUA) planes de área, estándares y exigencias de resultados en las pruebas estatales e internacionales, superar los bajos puestos que ocupa Colombia en cuanto a la comprensión de lectura y lectura crítica, entre otros; situación que ha llevado a que los objetivos de la educación colegial se enfoquen en cumplir dichos criterios que en consolidar una verdadera cultura lectora nacional.

Sin embargo, precisamente por esa urgente necesidad y presión de fortalecer los procesos lectores, en los últimos cinco años han sido fructíferas las investigaciones que relacionan la literatura con los procesos de lectura. En las fuentes bibliográficas consultadas es evidente que aún son vigentes las bases epistemológicas, pedagógicas y didácticas que han propuesto Colomer (1996, 1997a, 1997b, 2010), Barthes (1994), Bloom (1995), Giani Rodari (1973, 1999), Jorge Larrosa (1998), entre otros. A saber, como resultado de la revisión documental de esta categoría se puede indicar que se desprenden tres subcategorías de análisis: la 
literatura para el fortalecimiento de la comprensión lectora; la literatura para el desarrollo de pensamiento y la lectura crítica; y la literatura como generadora de experiencias de lectura. A continuación, se analizará cada una de ellas, de manera que se referencian algunos documentos académicos para ilustrar su desarrollo.

\section{La literatura para el fortalecimiento de la comprensión lectora}

En las últimas décadas, la promoción de la lectura ha sido relevante en toda Hispanoamérica como campo de actuación social; se considera una herramienta propicia para la participación ciudadana y para superar los mecanismos de exclusión tan frecuentes en el entorno hispanohablante. De ahí que son varios los esfuerzos de los profesores colombianos y latinoamericanos que se han enfocado no sólo en la alfabetización de la población, sino en "la formación de lectores críticos, autónomos y con capacidad de hacer diversos usos de la cultura escrita a favor de sí mismos y de los demás" (Robledo, 2010, p. 15).

Sanabria (2018) plantea como estrategia pedagógica para la enseñanza de la literatura y el fortalecimiento de la comprensión lectora la construcción de un nuevo canon literario para $9^{\circ}$ de bachillerato que motive y desarrolle la competencia interpretativa y el goce literario. Sanabria propone transformar el componente literario del plan de estudios de la asignatura de Lengua Castellana para que interese a los estudiantes, enriquezca la relación dialógica entre el lector y el texto, y genere "empatía entre el docente-estudiante durante el proceso de reconstruir, el abordaje, producción, análisis y comprensión de textos que es de suma importancia para fortalecer la crítica, la reflexión y el goce literario en la formación pedagógica" (p.19).

La autora considera que introducir la lectura de novelas escritas por mujeres para inducir la curiosidad lectora es una estrategia innovadora. Además, aclara que su intención no es plantear una literatura de género, sino "superar expectativas que ha dejado la tradición, para este caso reconocer el canon desde toda formación literaria" (p.43).

Diversos autores han usado la literatura para el fortalecimiento de la comprensión lectora, y esta labor es fundamental, ya que las directrices nacionales e internacionales están enfocando y limitando a la comprensión de lectura solo para ámbitos específicos académicos y profesionales. No se desmerita esta perspectiva, sino que es importante formar al estudiante desde la aproximación a diferentes tipos de textos y diferentes formas de leer. La lectura figurativa, simbólica y estética no puede perder su función social, pues antes que trabajadores o sujetos en acción de contextos particulares se es humano, esencialmente sujetos configurados por signos y creadores de signos.

\section{La literatura para el desarrollo de pensamiento y lectura crítica}

Uno de los aspectos más recurrentes en los últimos años es el rol mediador que se le otorga a la literatura como una herramienta para dinamizar el pensamiento crítico y la lectura comprensiva crítica de los estudiantes. Por ejemplo, Nicolás Ferger (2016) realizó una investigación-acción donde propone una secuencia didáctica que busca fortalecer las competencias literarias de estudiantes del grado $11^{\circ}$, a partir de la comprensión textual y lectura crítica. Incluye la literatura contemporánea colombiana para enriquecer los procesos cognitivos de apropiación textual y literaria. Para Ferger (2016), la literatura es un vehículo ideal que posibilita fortalecer la lectura crítica, la producción textual, y la apropiación de competencias literarias que "generen una nueva sociedad, más identificada con su cultura, sus simbologías, y sus componentes sociales como país y región” (p.26). 
También, se encuentra Efraín Posada (2019), quien realizó un estudio de caso con análisis metodológico cualitativo con alcance descriptivo para analizar la promoción de la lectura crítica en estudiantes de $8^{\circ}$ de bachillerato a través del uso de textos literarios. Entre los hallazgos de esta experiencia didáctica es que se posibilita desarrollar diferentes categorías de análisis en los estudiantes como la identificación de ideas, producción inferencial, juicios y construcción de conclusiones mediante la confrontación de ideas. De igual manera, según el autor esta estrategia didáctica favorece la capacidad para comprender sentidos implícitos, y elaborar deducciones en diferentes textos.

Por otro lado, figura el ensayo de Daniel Torres (2017), quien usa los principios de la pedagogía de interés de Friederich Herbart, la lectura crítica y la didáctica para construir una propuesta formativa literaria recreativa en espacios académicos de la educación media y superior. Su objetivo es transformar las prácticas lectoras en el aula para que los jóvenes desarrollen competencias comunicativas y pensamiento crítico; igualmente, mostrar la pertinencia de fomentar la lectura crítica a partir de textos recreativos para aproximar al estudiante a la lectura y la escritura antes de iniciar su etapa académica universitaria.

Su propuesta se fundamenta en cinco factores: a) Elegir libros acordes a la edad y temáticas de interés de los estudiantes y que este sea adaptable o con temática interdisciplinar. A modo de ejemplo, Torres (2017) elige la saga "Canción de Hielo y Fuego" asegurando que su lectura genera debates de temas cuestionables como el incesto, el regicidio, la sublevación, entre otros; b) elegir una obra de interés práctico y con la cual el estudiante se pueda identificar; c) que la obra sea llamativa por su contenido y extensión; d) utilizar medios de presentación innovadores, persuasivos y sugerentes de la obra; e) integrar un método evaluativo motivacional, no solo de verificación, sino de acompañamiento.

En este orden de ideas, múltiples estudios se han adelantado con relación a la literatura para el desarrollo de la lectura y pensamiento crítico. Esto enaltece la literatura desde su función analítica, reflexiva, un entramado hipervinculante que supone, no solo el reconocimiento del uso estético o técnico de la lengua, sino la capacidad de integrar en sus historias, dramas o poesía la complejidad del conocimiento y el sentir humano.

\section{La literatura como generadora de experiencias de lectura}

Esta idea no es novedosa, en los lineamientos curriculares de Lengua Castellana propuestos por el MEN se expresa: "Nos referimos entonces al estudio de la literatura no como acumulación de información general: periodos, movimientos, datos biográficos, sino como una experiencia de lectura y de desarrollo de la argumentación crítica" (p.56). Además, este documento plantea que el estudio de la literatura se puede desarrollar desde tres posibles paradigmas o dimensiones teóricas: la estética, la historiografía-sociología y la semiótica.

Michéle Petit (2001) afirmó que el acto de leer es una experiencia que convoca la memoria, el intelecto, la imaginación, los sentimientos, anhelos, pasiones y deseos. También Jorge Larrosa (2003) habló de la experiencia transformativa que supone leer, según el autor, la literatura hace que el lector interactúe, que le sucedan cosas que lo pueden transformar o deformar, pero de ninguna manera dejar igual.

La experiencia lectora literaria se convierte en un estado de emergencia imaginativa, un experimento que capta el saber personal y colectivo. A través de la literatura se convergen experiencias estéticas con la razón y la imaginación, confluyen nociones y emociones como el pivote para configurar actitudes o sentidos comprensivos ante las representaciones del mundo. 
Como posibilidad de crear vivencias literarias estéticas, se cita a Elizabeth Tabla (2015). $\mathrm{Su}$ investigación tiene dos finalidades: a) construir marcos teóricos de referencia sobre didáctica literaria para el análisis poético desde la perspectiva fenomenológica de Gastón Bachelard y b) consolidar un trabajo didáctico-poético que busca recuperar la experiencia de la palabra poética en el aula, su valor estético y sensible. Para esto, sistematiza experiencias como metodología de investigación social. La autora concluye que la poesía ha sido olvidada por la mercadotecnia y los discursos comerciales, además, en la didáctica de la literatura hay una tendencia a las teorías prescriptivas, conceptuales y cognitivas, más que al desarrollo de experiencias en clase. Sugiere que los profesores de literatura deben aproximarse a una verdadera sensibilidad poética para poder contagiarla a sus estudiantes. Esta vivencia como experiencia y acontecimiento lector debe superar los límites de la aprehensión racional y privilegiar la emoción subjetiva.

La lectura como experiencia lectora es un proceso que depende de las estrategias didácticas del docente para brindar al estudiante una cercanía al simbolismo literario, al lenguaje figurativo, a los efectos de una trama, a la cercanía temática.

A este respecto Mery Cruz (2019) realizó una investigación cualitativa donde utilizó la etnografía educativa para caracterizar algunas mediaciones docentes en la formación literaria de estudiantes de básica secundaria y media de colegios de la ciudad de Cali. Buscó identificar y sistematizar intervenciones didácticas de los docentes que logran fortalecer, o no, las competencias lectoras de los jóvenes a partir de sus experiencias de lectura. Los resultados muestran que la transposición didáctica es fundamental, puesto que permite adaptar y adecuar los elementos y el metalenguaje de la teoría literaria al espacio escolar, en este sentido, el estudiante no necesita ser especialista para poder analizar una obra. De igual forma, la investigadora encontró que, aunque el docente activara estrategias de mediación y acompañamiento en las lecturas, los jóvenes rechazaban la literatura que trataba de temas que discreparan con sus intereses, lo que impide construir experiencias significativas de lectura.

Cruz (2019) explica que la mediación del docente para la formación de un lector es diferente en cada caso; a partir del análisis de las experiencias de lectura que estudió, identificó tres tipos de mediaciones didácticas: la omnipresente (relacionada con un acompañamiento continuo de la docente en diferentes ámbitos del proceso lector, sus recepciones ante el texto indican entusiasmo y motivación por la lectura y el trabajo), la presente (busca formar intérpretes críticos, que analicen obras literarias desde un carácter más académico) y la distante (implica que hay una orientación del docente, se proporciona información socio-contextual sobre la historia de la obras, pero al momento de leer, los estudiantes no logran una recepción de acogida del texto, pues se sienten lejanos al texto).

La literatura como experiencia de lectura supone crear procesos de sensibilización y acercamiento con narrativas y líricas que van más allá de lo meramente comprensible desde lo literal, inferencial y crítico-intertextual. La experiencia lectora implica desarrollar criterios estéticos y de recepción, que el estudiante se sumerja en los estados patémicos de los personajes, logren sentir el conflicto, las emociones y pensamientos que se dan en medio de las historias o los yo-poéticos, pueda percibir ese mundo literario que se le ofrece y de alguna manera, se deje afectar, tocar o sacudir.

\section{Categoría: Literatura para la escritura creativa}


La creación literaria no ha tenido el mismo protagonismo investigativo y de práctica en el aula como la lectura, la cual se ha considerado como el centro de la educación literaria (Colomer, 2010, Dueñas, 2013). En Colombia, se cuenta con espacios extraescolares que tienen como objetivo la formación y promoción de la escritura creativa y que han nacido por iniciativas particulares de centros culturales, tales como Centro de desarrollo artístico Compaz, Fundación La Cueva en Barranquilla, la Fundación Fahrenheit 451, La Fundación Escribir no muerde en Cali, Corporación Comunicar o Liebre lunar en Bogotá, Rayuela en Cúcuta, entre muchos otros, así como también se encuentran los estímulos estales que se han proporcionado a través de la Red Nacional de Escritura Creativa (RELATA) y los aportes de diversos grupos de investigación universitarios y programas de pregrado y posgrado. No obstante, todos estos siguen siendo procesos formativos que son externos al currículo oficial del bachillerato.

En la obras de Saavedra $(2011,2013,2017)$ se ha reflexionado sobre el estado marginal de la escritura creativa literaria en la educación básica y secundaria de Colombia, puesto que la producción textual se incentiva como producto de lo leído (a manera de comentario de texto) o para reproducir conocimientos disciplinares o evaluar el uso de la lengua. "Tal cosificación del código escrito omite sus propósitos de expresión, creación o invención para configurar otros mundos reales, probables y posibles" (Saavedra, 2020, p.6). El mismo autor realiza una investigación de marco antropológico-pedagógico (2020), y propone una formación (Bildung) literaria que reivindica la escritura como acto de creación ficcional, en el cual los estudiantes pueden expresar sus habilidades estéticas e indagar sus propias condiciones humanas, se posibilita que explore otras posibilidades del existir y ser.

De esta manera, Saavedra (2020) argumenta que la formación de competencias escritas va más allá de las técnicas generales de composición-redacción y se consolida en una propuesta que complementa la comprensión lectora, base de la educación literaria y su didáctica específica. El Bildung literario enfatiza en los aspectos estéticos, sensibilidad e invención de mundos alternos (poiesis) que evoquen valores universales humanos desde experiencias concretas del estudiante. De aquí, que la creación tienen como base los presaberes (el uso del lenguaje y la cotidianidad vivida) para hacer un viaje interior y construir a través de los sentidos expresiones estéticas.

Sebastián Gracia (2019) realizó un estudio cualitativo de alcance descriptivo que buscó promover procesos de escritura creativa en estudiantes de básica secundaria y media del Colegio San Luis de Zipaquirá. Para esto, integra el modelo pedagógico constructivista desde los enfoques de Piaget (1950), Vygotsky (1938) y Ausubel (1960) y Bruner (1972), con el fin de fortalecer la creatividad y el pensamiento crítico de los jóvenes, e igualmente, diseña y aplica técnicas y herramientas didácticas desde la literatura y se enfoca en las propuestas de Rodari (1973), de manera que usa como referentes diferentes géneros: narrativo, poético, dramático y didáctico. Esta estrategia le permitió desarrollar procesos de pensamiento tanto lógicos, como fantasiosos; facilitó que cada estudiante pudiera aplicar los saberes adquiridos desde su cotidianidad y propia existencia; expresar su opinión y encontrar un espacio de discusión grupal que le facilita socializar y retroalimentar sus creaciones, todo esto no solo promueve el ejercicio escritor, sino además, estimula la apreciación de los componentes literarios, sus estructuras ficcionales y la oportunidad de que el estudiante sea promotor de su propio aprendizaje.

Entre los resultados, Gracia (2019) menciona el reducido tiempo de clase, lo que dificulta la profundización y la experimentación entorno a la creación literaria, "si bien es indispensable que los estándares y planes curriculares sean cumplidos a cabalidad, es 
importante también que los estudiantes encuentren en sus clases escolares, espacios destinados a la creación y a estimular las habilidades blandas" (p.4). Se observó que falta integrar en las prácticas educativas técnicas literarias que fortalezcan el pensamiento creativo, la valoración-apreciación literaria, el juego, y la comprensión de mundos fantásticos. Es evidente que aún reinan actividades escriturales tradicionales como el dictado, los concursos de ortografía, deletreo, etc., lo que invita a apuntar urgentemente prácticas innovadoras de sensibilización y motivación.

Este tipo de experiencias creativas motivan a escribir y leerse. En efecto, cerrar espacios educativos para la creación escrita, limita el conocimiento de la literatura y obstruir la capacidad humana de producir estructuras poéticas, narrativas y dramáticas desde sus experiencias individuales, colectivas, ficticias, discursivas y sociales. Hay que superar la creencia de que la escritura literaria solo puede ser una práctica de especialistas.

\section{Categoría: La literatura en la Didáctica de la Lengua Materna y en los Nuevos Estudios de literacidad}

En las primeras páginas de este artículo se mencionó que en Colombia no existe la asignatura de Literatura en el Bachillerato del sector oficial, esta se enseña como un componente curricular de la asignatura de Humanidades y Lengua Castellana. Cisneros, Rojas y Olave (2016) aportan a la discusión actual en torno a la didáctica de la lengua materna en Colombia, reflexionan sobre la fragmentación curricular, didáctica y pedagógica de los enfoques comunicativos y la ciencia lingüística, instauradas por las políticas curriculares desde el modelo de competencias, de aquí, que para ellos sea urgente desfragmentar los procesos de enseñanza-aprendizaje de la lengua, se supere la formación por contenidos, pero también se valore sus aportes. Igualmente, proponen fortalecer la profesionalización docente en las licenciaturas colombianas, puesto que, según los investigadores, es fundamental que los maestros de colegio puedan adaptar, adecuar y apropiar el conocimiento disciplinar de la lingüística teórica al contexto institucional escolar a las necesidades de sus estudiantes. Sí, construyen tres experiencias didácticas que buscan desfragmentar la enseñanza de la lengua en el aula, de forma que se aprendan, se crean y se piensen realidades a través de la lectura y la escritura.

Lo interesante de las propuestas y que se relaciona con el objetivo de este artículo, es que Cisneros et al (2016) articulan la enseñanza de la lengua desde el uso de diferentes tipos de textos. En el caso de los textos literarios, le dan una utilidad didáctica para propiciar el goce estético y la creación escrita; apuestan al uso de la literatura clásica para trascender el aprendizaje basado en conceptos y revisión de fechas y autores para pasar a una lectura inmersa en la historia, la reflexión, las conexiones intertextuales que se pueden establecer, la valoración del mundo literario y el real, los sistemas de significación, el valor estético del lenguaje y la creatividad de los estudiantes: "buscamos la posibilidad de potenciar en los jóvenes lectores una experiencia de encuentro significativo con la historia narrada, sus personajes y el contexto sociocultural en el que se inscribe" (p.77).

Otro aporte significativo es la tesis de maestría de Lora y Moreno (2020), quienes analizaron las tensiones en las prácticas de enseñanza-aprendizaje de la literatura desde los Nuevos Estudios de Literacidad (NEL), en el contexto de dos instituciones educativas del suroeste antioqueño. Para las autoras es evidente que en el último siglo se han consolidado nuevas concepciones ante la metodología de enseñar la literatura desde perspectivas semióticas, estéticas, lúdicas y de géneros literarios, sin embargo, ellas también aluden que 
estas metodologías son fragmentadas, y que se desarrollan dependiendo del gusto del docente, desvirtuando la opinión del estudiante.

De igual manera, identifican que los currículos se siguen enfocando en tres estilos de enseñanza literaria: estructuralista, historiográfica y semántica comunicativa; siguen prevaleciendo los enfoques que instrumentalizan la enseñanza de la literatura, que se centran en los contenidos lingüísticos y estructurales. De aquí que Lora y Moreno (2020) insisten en consolidar una enseñanza de la literatura que supere los currículos tradicionales y los parámetros establecidos por el MEN y el modelo de competencias, los cuales fueron publicados hace más de veinte años. Las investigadoras proponen una enseñanza de la literatura donde los discursos de la literacidad y la construcción social de los sentidos se centre atendiendo a lo que hacen los estudiantes con lo que leen y escriben en la escuela, cómo lo hacen y para qué lo implementan en su vida académico-universitaria y comunitariavital. Es decir, la enseñanza de la literatura desde las nuevas formas de literacidad, supone analizar y sensibilizarse ante la literatura acorde a los "contextos de uso, el disfrute estético, el reconocimiento de las voces, los sentidos y otros elementos discursivos, que constituyen acercamiento más prácticos a los textos y a sus maneras de producirse" (p. 14) .

El Grupo de investigación de la especialización de Didácticas de las Lecturas y Escrituras con énfasis en Literatura de la Universidad San Buenaventura (2015), publicó un artículo de revisión sobre la enseñanza de la literatura en Colombia de 1990 a 2015 desde una propuesta arqueológica, que permite buscar y analizar textos y discursos que se han configurado desde las aulas de clase y que faciliten comprender la situación actual de la enseñanza de la literatura en la nación, su influencia en la formación humanística, y su relación con la escuela, la familia y la tecnología. Los investigadores concluyen que la relación escuela-literatura está en crisis; las problemáticas sociales en los contextos familiares, la brecha de desigualdad entre la educación pública y privada, el desarrollo de la literacidad electrónica (nuevas formas de leer y escribir mediadas por las tecnologías de la información), entre otros, han consolidado grandes desafíos para la enseñanza de la literatura. En este sentido, es pertinente reconocer la literatura como mediadora que forma de manera integral, en valores sociales, humanos, culturales.

Por otra parte, Montes (2020) presenta un análisis crítico de tres políticas educativas colombianas que han orientado la enseñanza de la literatura en el sector oficial en los últimos 25 años. Se expresa un interés hermenéutico frente a las fundamentaciones literarias estatales y un interés emancipatorio de las escuelas frente a las políticas educativas neoliberales. El autor invita a reivindicar la educación literaria desde su carácter estético para formar y transformar a los estudiantes desde la relación con sí mismos (autopoiesis) y con el entorno social (intersubjetividad).

Así pues, se propone un repertorio didáctico para la enseñanza de la literatura que compendia las contribuciones teóricas y pedagógicas de defensores de la educación literaria con el fin de explorar otras formas de enseñar la literatura, ya que, según Montes (2020), al estudiar las políticas educativas relacionadas con el área del lenguaje se refleja "la inexistencia de una educación literaria de carácter estético, en la que los estudiantes exploren la configuración de su subjetividad en relación con la lectura, el análisis y la composición de obras literarias" (p.111). En ese mismo orden de ideas, el autor alude que la enseñanza de la literatura en los planes curriculares es un contenido más entre los otros establecidos lo que causa que los procesos de enseñanza-aprendizaje literarios no tengan el reconocimiento y autonomía necesarios. 
Esta categoría permite analizar críticamente la fragmentación en la enseñanza de la lengua materna y la literatura junto con las disciplinas y enfoques que las teorizan y la llevan a la práctica pedagógica Se propone formar lectores y escritores literarios, críticos y autónomos, que tengan capacidades actitudinales, académicas y artísticas no solo para comprender, sino también para disfrutar y compartir la composición e interpretación de obras literarias a lo largo de su vida, que no solo se limiten a los contenidos escolares. En el marco de esta formación, "la educación literaria acontece como un dispositivo estético para el conocimiento y la configuración de la subjetividad (auto-poiesis), al tiempo que emerge como una plataforma política para el reconocimiento social, el sentido crítico, el pensamiento utópico y la transformación de la realidad (inter-subjetividad)" (Montes, 2020, p.111).

\section{Uso de otras estéticas (La música y el cine) para el desarrollo de competencias literarias}

El Proyecto colombiano de promoción de lectura "A leer sin fronteras" (2017) financiado por el Centro Regional para el fomento del libro en América Latina y el Caribe- CERLALC propone un programa dirigido a la población infantil y juvenil de las instituciones educativas del municipio de Miranda, Cauca, en el que se introducen diferentes manifestaciones artísticas y lenguajes expresivos y estéticos para fomentar la comprensión lectora y la sensibilidad literaria. La idea es que los estudiantes amplíen sus juicios frente a las diferentes formas de leer, comprender e interpretar la multiplicidad de signos que provienen de diversas fuentes y lenguajes verbales y no verbales.

Igualmente, Álvaro Suaza (2017) presenta una monografía donde describe la propuesta pedagógica "Musiclases Literarias", aplicada en los grados sexto, noveno y undécimo de bachillerato del Liceo Femenino Mercedes Nariño; su intención es articular los recursos musicales con las temáticas literarias de cada grado y reforzar las competencias lingüísticas y discursivas de los estudiantes. La monografía reflexiona sobre la literatura, la música y sus posibles interacciones didácticas en el aula. En un primer capítulo, se explica el concepto de literatura y su relación estética con el arte musical, en concreto se habla de la expresividad en la poesía y como de allí subyacen composiciones literarias que también se emplean en la producción musical. También, se explora las figuras de la música popular, como el trovador medieval, las funciones melódicas y didácticas de la copla, y la consolidación del género textual-musical de la canción. En un segundo capítulo se hace una exégesis musical de diversas obras literarias contemporáneas de autores como Guillermo Cabrera, Juan Manuel Puig, Roberto Burgos Cantor, Andrés Caicedo y Rafael Chaparro. En el tercer capítulo se estructura la propuesta didáctica y pedagógica de las "musiclases literarias", las cuales

Se fundamentan en la apropiación de diversas herramientas musicales a nivel discursivo, semántico e incluso pragmático a través del contenido de sus letras como dispositivo para enriquecer los planes curriculares planteados en los diferentes niveles en el área de Humanidades y Lengua Castellana; donde a través de las mismas se genere una postura respecto a los temas presentes de manera implícita y explícita y cómo estos temas permiten una reflexión vivencial sobre temas cotidianos que permita generar voces desde diversas posturas ideológicas enriqueciendo en el aula la multiculturalidad. (Suaza, 2017, p.37)

En el último capítulo, Suaza (2017) concluye que este tipo de estrategia didáctica posibilita ampliar los modos de lectura, recrearla a través de la aproximación e interpretación 
de diversas experiencias estéticas o en actividades de su diario vivir. Incluir la música en la clase de literatura fue provechoso, ya que logró aumentar el interés de los estudiantes, pues se vincularon contenidos poco habituales y se fomenta el rol de la literatura en la consolidación de la identidad del ser humano.

En otros ámbitos estéticos, durante los últimos veinte años, la relación del cine con la literatura se ha fortalecido en las prácticas educativas, por tanto, son múltiples las propuestas didácticas de su uso para el desarrollo de competencias literarias; desde la promoción de la escritura elaborando guiones cinematográficos, pasando por el análisis intertextual de obras literarias en comparación con sus adaptaciones audiovisuales, hasta la producción de contenido audiovisual de narraciones creadas por los estudiantes. A manera de ilustración de la vigencia del uso del cine para la enseñanza de la literatura, se cita a Luz Elvira Miranda (2019), quien centra su interés en fortalecer el reconocimiento de la identidad cultural en la educación secundaria y en la necesidad de invitar a los docentes a diseñar e implementar estrategias novedosas que contribuyan a la enseñanza de la literatura. Para lo anterior, esta profesora propone aproximarse a la literatura latinoamericana a través del uso del cine-foro como una estrategia para el desarrollo de conocimiento cultural, tradicional, histórico y mítico de los pueblos.

Miranda (2019) diseña cuatro actividades dirigidas a estudiantes de grado noveno de la Institución Educativa departamental Santa Ana (Soacha, Cundinamarca), en las cuales se integran los contenidos audiovisuales junto con fuentes literarias clásicas como el "Popol Vuh”, “PPor qué me llevas al hospital en canoa papá?”, "Pedro Páramo” y "Martín Fierro”, de manera que rescata elementos culturales dentro de la literatura latinoamericana, proporciona contenidos pedagógicos diversos pero atendiendo al canon literario clásico latinoamericano, cargado de valores culturales, trabajadas desde el ámbito formal y lúdico. En este sentido, la autora considera que el cine foro es una herramienta pedagógica que permite desarrollar en los estudiantes gusto por la lectura literaria, así como también, posibilita la reflexión, el sentido crítico y el placer por interactuar con otros sistemas simbólicos, como lo es el cine.

En general, es usual el uso de otras estéticas o sistemas simbólicos para la enseñanza de la lengua y la literatura, pero es claro que la proliferación de nuevos contenidos musicales y audiovisuales y el fácil acceso a estos materiales dado por la libre circulación de la información han fortalecido y transformado las prácticas educativas de la enseñanza de la literatura, han configurado nuevas formas de consumo, han activado otras formas de interpretación y lectura más allá del código escrito. Las letras se han adaptado a nuevos formatos como una forma de conservación artística, pero también como una demostración de su capacidad simbólica, de reinvención y de testimonio de las nuevas identidades, de los nuevos intereses generacionales.

\section{La Cibercultura en el desarrollo de competencias literarias}

Las nuevas prácticas de la cultura digital en concordancia con la evolución tecnológica y comunicativa han transformado las formas de interacción humana, y han abierto una reflexión ante los cambios organizacionales, curriculares, pedagógicos y didácticos que han tenido que afrontar las instituciones educativas. Desde finales del siglo XX, múltiples autores han abierto el debate y la reflexión sobre las nuevas configuraciones culturales y sociales dadas por la evolución tecnológica e informativa, como por ejemplo los conceptos de posmodernidad de Lyotard y Rato (1989), la Cibercultura definida y caracterizada por Levy (2007), la Sociedad de la Red de Castells (2006), las críticas y desafíos de la modernidad 
líquida de Bauman (2007), la Sociedad de la Ignorancia de Brey, Campás y Mayos Solsona (2009), entre otros. Dichos estudiosos tienen en común su comprensión ante la ruptura de la sociedad tradicional y cómo el mundo actual subyace en el marco de lo incierto, la complejidad y la fragmentación. Desde la aparición del internet, la sociedad entró en la revolución informativa; se configuraron nuevas formas de pensar, de acceder y circular el conocimiento, de leer, de escribir, de hablar, se han creado nuevos lenguajes, nuevos signos y nuevos contextos que han desafiado al maestro y a todo el sistema educativo.

En el caso de la Cibercultura en el desarrollo de las competencias literarias, Dina Paternina (2017) elabora una investigación de corte descriptivo y propone estrategias didácticas con enfoque constructivista para trabajar los textos clásicos literarios del plan lector del grado noveno de secundaria, a través del uso de plataformas, programas y/o redes tecnológicas informativas como: YouTube, Storyboard, Moviemaker, Audacity, Spreaker, Powtoon y Facebook; su interés es motivar a los estudiantes frente a su proceso lector y fortalecer sus competencias como creadores de contenido articulando la literatura en sus producciones audio-visuales, escritas y orales, además de servir de apoyo al Plan Nacional de Lectura y escritura de Colombia (2016). Según la autora:

El uso de las herramientas TIC permite no solo que los estudiantes fortalezcan sus competencias como ciudadanos globales, sino que, además, podrán observar los contenidos que circulan desde puntos de vista más críticos, generando otras formas de leer. (Paternina, 2017, p.6)

Se destaca que la propuesta es fundamentada en cuanto a la complejidad del proceso de enseñanza-aprendizaje que supone incluir las TIC en las prácticas lectoras literarias en el contexto colombiano, además que posibilita el fortalecimiento de diversas habilidades comunicativas: la escritura de guiones, resúmenes, la selección de información, de imágenes, la capacidad de síntesis y el uso correcto de la lengua.

Por otro lado, Jorge Eliécer Pacheco (2016) realizó una investigación-acción donde implementó la red social Facebook como herramienta para el trabajo colaborativo en la escritura de cuentos de los estudiantes de noveno grado de un colegio en Piedecuesta, Santander. El autor aplicó para su análisis las fases analíticas propuestas por Elliot y McKernan para identificar los juicios epistémicos que los estudiantes le atribuían a la escritura en Facebook con relación a la composición literaria de cuentos. De aquí, se concluyó que la red social puede tener una funcionalidad didáctica y pedagógica, puesto que posibilita la interacción, socialización y creación de redes de colaboración para el trabajo creativo escrito de los estudiantes, quienes encuentran en el Facebook una posibilidad de compartir sus producciones y recibir críticas para mejorar habilidades de composición.

También se encuentra la investigación-acción de la licenciada Andrea Bustos (2019) quien determinó la incidencia del Booktube como herramienta didáctica para mejorar el hábito lector y desarrollar competencias literarias en los estudiantes de $8^{\circ}$. La autora concluye que el Booktube posibilitó la promoción literaria, pues permite que los estudiantes tengan una aproximación lúdica con la lectura, y brindó otras perspectivas estéticas de las historias y otro tipo de experiencia frente a la literatura. Adicionalmente, se usaron herramientas TIC como Google classroom, YouTube y Facebook, que facilitaron y promovieron la articulación de aprendizajes, la integración entre docente-estudiantes para compartir y valorar las creaciones y abrió un espacio para la reflexión frente a percepciones y modos de actuar en la red. 
Adicionalmente, se encuentra el trabajo de investigación de Jorge Alberto Sierra (2019) quien desarrolla la competencia narrativa en estudiantes de noveno grado de la Institución Educativa Distrital Juana Escobar (Bogotá). Para esto el autor diseña una estrategia didáctica virtual utilizando el Comic digital, donde los estudiantes crean sus propias narraciones gráficas de manera autónoma y colaborativa en concordancia a procesos de lectura previa de cuentos clásicos latinoamericanos y el reconocimiento de los elementos de contenido y estructura textual. Para hacer los comics se propuso el uso de aplicaciones web como Pixton y ToonDoo y se realizó un proceso de acompañamiento para la creación literaria desde el reconocimiento del estudiante frente a su contexto sociocultural.

Sierra (2019) articula el enfoque constructivista, el aprendizaje significativo, la tecnología educativa crítica y el conectivismo desde la concepción de pedagogías emergentes en su propuesta didáctica para el desarrollo de competencias narrativas literarias. Además, aplica el modelo TPACK (Conocimiento Técnico Pedagógico del Contenido), el cual posibilita que el profesor unifique los saberes tecnológicos, pedagógicos y de contenidos de la asignatura de español y literatura junto con un diseño instruccional ADDIE (análisis, diseño, desarrollo, implementación y evaluación).

En esta categoría se puede encontrar que las propuestas didácticas literarias mediadas por las TIC resultan motivantes para los estudiantes, pues son próximas a las prácticas cibernéticas de su generación, pero también es importante esclarecer que implica un esfuerzo mancomunado del grupo de estudiantes, padres de familia, y del profesor a quien le recae no solo la mediación literaria, sino también la orientación en el uso de las herramientas, aplicaciones y programas de creación de contenido digital, auditivo y audiovisual, una tarea que es enriquecedora, pero desafiante ante la precariedad de recursos, tiempo y de actitudes de negación con los que se encuentra en las realidades del sistema educativo colombiano.

Como todo proceso cultural, la Cibercultura implica la participación y conocimiento de sus prácticas, técnicas y la apropiación de una identidad tecnológica. Este proceso aunque es masivo a nivel mundial por los fenómenos de la globalización y posmodernidad, no es del todo desarrollado en sociedades de escasos recursos, desigualdad y la corrupción, donde ni siquiera existen los servicios básicos de luz y agua y en consecuencia, no existen las posibilidades de acceso y adquisición tecnológica. Es evidente que la literatura se ha transformado y se ha reinventado en nuevos géneros audiovisuales y también se han creado múltiples plataformas y aplicaciones para creación de contenido que puede ser aplicados para el desarrollo de competencias literarias.

\section{Conclusiones y recomendaciones}

La literatura dentro de la formación secundaria es un hipervínculo con otras disciplinas del saber y con otros componentes del mismo lenguaje, se utiliza como pretexto y como objeto intertextual para relacionar conceptos, desarrollar habilidades y fortalecer competencias con un fin educativo institucionalizado. Esto puede deberse a lo que Cisneros et al (2016) identifican como una desfragmentación de la didáctica de la lengua materna y que de manera directa, también se manifiesta en la didáctica de la literatura. 
El recorrido por las diferentes categorías de la didáctica de la literatura en la educación secundaria y media en Colombia (teóricos, prácticos e investigativos) invita a preguntarse ¿Cuáles deben ser los fines de la enseñanza de la lectura y la escritura? ¿Por qué la literatura solo como un medio para desarrollar habilidades de lenguaje y no como un fin formativo en sí mismo? Es evidente que la costumbre prescriptiva de la regulación recae sobre los objetivos del currículo, la cual obliga que la enseñanza de la literatura se alinee con los discursos dominantes que estructuran la política curricular, afectando así, el rol artístico, de sensibilización, experiencial, creativo y de construcción de una verdadera cultura literaria y de apropiación lectora integral.

Por otro lado, la literatura sigue teniendo diversas posturas frente a su definición y funcionalidad en la educación, lo que hace que para algunos sea arte, para otros sea un posible campo del conocimiento, una disciplina o una ciencia, incluso algunos la catalogan como una actividad ociosa sin utilidad alguna. No obstante, la literatura ha sido uno de los principales medios artísticos de expresión que difunden la habilidad creativa, estética y simbólica de la humanidad y ha permitido conservar la memoria cultural, ideológica y artística a través de la historia. De hecho, se ha transformado en sus prácticas de composición, expresión, publicación y análisis en atención a las nuevas realidades posmodernas y de Cibercultura. Para Lineros (2000):

La literatura sirve para enriquecer, preparar, esclarecer, despejar y dotar a los hombres y mujeres de hoy y de cualquier momento de mayores y mejores armas para afrontar los desalientos y las contradicciones de la vida en tres aspectos fundamentales:

En el nivel individual: contribuye a la formación tanto humana como estética del individuo.

En el nivel social: contribuye a formar una sociedad nueva al servicio de la libertad, dignidad y solidaridad; así como al servicio de la cultura.

En el nivel técnico: contribuyendo al perfeccionamiento del uso del lenguaje (comprensión y expresión escritas). (p. 6)

Reconocer la literatura como creadora de culturas, como transformadora que sensibiliza no solo estéticamente al estudiante, sino que lo conecta con los valores culturales y sociales que han enmarcado la identidad universal de los pueblos y ciudades, permite considerar el papel de la literatura como una experiencia formativa integral y de adquisición del medio de comunicación más importante de la sociedad: el lenguaje.

Dado que la enseñanza de la literatura está enmarcada dentro de la enseñanza de la lengua materna y la literacidad, pocas son las investigaciones que se centran en una didáctica de la literatura propiamente dicha. Esto quiere decir que en la educación secundaria y media se privilegia la enseñanza de las habilidades comunicativas a través de la literatura y otros tipos de textos. Aunque sigue vigente su enseñanza desde la historiografía o de cánones tradicionales, las últimas investigaciones y propuestas didácticas están apostando por reconsiderar los criterios literarios establecidos y reformular, atendiendo a los intereses actuales de los estudiantes, diferentes voces narrativas y poéticas.

En términos generales, la educación en Colombia, junto con la de diversos países latinoamericanos, tiene el gran reto en el cultivo de la formación literaria y desarrollo de competencias lectoras y escritoras, incluso su enseñanza y didáctica se complejiza al ser país diverso y multicultural que presenta realidades sociales y educativas diferenciales entre las 
regiones; el desarrollo económico es variable según la demografía y existen situaciones políticas divergentes a niveles departamentales. Sin embargo, las directrices y orientaciones curriculares del Ministerio de Educación en Colombia están establecidas y normalizadas para todo el territorio nacional, estandarizando las competencias de aprendizaje y desconociendo las desigualdades sociales, de acceso, recursos y demás que se halla en el país. Todo esto, dificulta las prácticas de los docentes, quienes en su preocupación por enseñar debe adaptar sus acciones didácticas y pedagógicas al contexto de cada comunidad educativa, pero con la presión de cumplir las exigencias de los índices formativos nacionales e internacionales; asimismo, se desvirtúa el reconocimiento y utilidad formativa de la literatura frente a las otras disciplinas.

Finalmente, estos modelos didácticos revisados son un marco de referencia para el diseño de todo un proceso de enseñanza y aprendizaje de acuerdo a las necesidades institucionales, sociales y culturales, y que visibilizan la necesidad de actualizar y transformar los lineamientos estatales en cuanto a la enseñanza de la literatura, que no puede seguir siendo un mero componente de la lengua materna, sino que amerita una reivindicación de su rol educativo y artístico para la construcción de una cultura no solo nacional, sino universal, teniendo presente el marco de un realidad globalizada que obliga a pensar en ciudadanos para el mundo.

\section{Referencias bibliográficas}

Álvarez, L. (1991). Enseñanza de la literatura en la educación secundaria. En: Tratado de Educación Personalizada (Comp. Víctor García Hoz). Madrid: Ediciones RIALP.

Ausubel, D. (1960). The use of advance organizers in the learning and retention of meaningful verbal material. Journal of Educational, 51(1), 267-272. https://doi.org/10.1037/h0046669

Barthes, R. (1994). El susurro del lenguaje. Más allá de la palabra y la escritura. Barcelona: Paidós.

Bauman, Z. (2007). Los retos de la educación en la modernidad líquida. Barcelona: Gedisa

Bloom, H. (1995). El canon occidental. La escuela y los libros de todas las épocas. Barcelona: Editorial Anagrama.

Bloom, B.S. and Krathwohl, D. R. (1956). Taxonomy of Educational Objectives: The Classification of Educational Goals, by a committee of college and university examiners. Handbook I: Cognitive Domain. New York: Longman, Green.

Brey, A., Innerarity, D. \& Mayos, G. (2009). La sociedad de la ignorancia y otros ensayos. Barcelona: Infonomia

Briones. G. (2010). Teorías de las Ciencias Sociales y de la Educación. Epistemología. México: Editorial Trillas.

Bruner, J. (1972). Hacia una teoría de la construcción. Ciudad de México, México: Ed. Paidós

Bustos, A.M. (2019). Booktubers en el aula: desarrollando hábitos lectores y competencia literaria. Bogotá: Universidad Pedagógica Nacional. 
Cabarcas, Y.P. (2020). El cómic al aula: una didáctica narrativa. Revista Educación y Ciudad (38), pp. 125-134. https://doi.org/10.36737/01230425.n38.2020.2325

Camilloni, A. (2008). El Saber didáctico. Argentina: Paidós.

Castells, M. (2006). La sociedad red: una visión global. Madrid: Alianza Editorial

Cely, A. y Moreno. N. (2016). Ciudad y literatura: una posibilidad para aprender y enseñar geografía. Bogotá: Universidad Pedagógica Nacional.

Cisneros, M., Rojas, I., Olave, G. (2016). Hacia la desfragmentación de la didáctica de la Lengua Materna. Pereira: Universidad Tecnológica de Pereira

Colomer, T. (1996). La didáctica de la literatura: temas y líneas de investigación e innovación. Capítulo III.3. En LOMAS, C. (coord.). La educación lingüística y literaria en la enseñanza secundaria. Barcelona: ICE Universitat Barcelona-Horsori, pp. 123-142.

Colomer, T. (1997). La didáctica de la literatura. En AAVV, La educación lingüística y literaria en la etapa secundaria. Barcelona, Horsori.

Colomer, T. (1998a). La formación del lector literario. Madrid, Fundación Germán Sánchez Ruipérez.

Colomer, T. (1998b). La poesia com a expressió de sentiments. En A. Camps y T. Colomer (coords.), Didàctica de la llengua i la litera

Colomer, T. (2010). Introducción a la literatura infantil y juvenil actual. Madrid: Síntesis.

Congreso de Colombia. (8 de febrero de 1994). Ley General de Educación. [Ley 115 de 1994].

Congreso de Colombia. (julio de 1991).Constitución Política de Colombia. Art. 22 de julio de 1991 (Colombia).

Contreras, J.D. (1994). Enseñanza, Currículum y Profesorado. Introducción Crítica a la didáctica. España: Universidad de Málaga.

Cruz, M. (2013). Lectura literaria en secundaria: la mediación de los docentes en la concreción de los repertorios lectores. Barcelona: Universidad de Barcelona.

Cruz, M. (2019). Mediación docente en la lectura literaria en secundaria. Campo Abierto, 38, p. 5-18. https://doi.org/10.18239/ocnos_2019.18.3.2108

Dardel, E. (1952). L 'homme et la terre. París: PUF.

Dueñas, J. (2013). La educación literaria. Revisión teórica y perspectivas de futuro. $\begin{array}{lllll}\text { Didáctica. } & \text { Lengua } & y & \text { literatura, } & 25,\end{array}$ https://doi.org/10.5209/rev_DIDA.2013.v25.42239

Eguinoa, E.A. (2016). Didáctica de la literatura: proceso comunicativo. México: Universidad Veracruzana.

Espectador. (abril 5, 2018). Según el DANE, en Colombia se lee más. https://www.elespectador.com/noticias/cultura/segun-el-dane-en-colombia-se-lee-masarticulo-748374

García, E. (2017). La reconstrucción de la identidad social colombiana a partir de algunas obras literarias contemporáneas: [Recurso electrónico] Un estudio de la producción inicial de Gabriel García Márquez. Granada: Universidad de Granada, 2017. http://hdl.handle.net/10481/46969

Gracia, S. F. (2019). La creación literaria y el aprendizaje constructivo, promotores de jóvenes escritores. Centro Sur, 3, (2). https://doi.org/10.31876/cs.v3i1.20

Grupo de investigación de la especialización de Didácticas de las Lecturas y Escrituras con énfasis en Literatura Universidad San Buenaventura. (2015). Arqueología de la enseñanza de la literatura en la educación colombiana desde la formación humanística. 
Revista Interamericana de Investigación, Educación y Pedagogía, 8 (1), pp. 25-46. https://doi.org/10.15332/s1657-107X.2015.0001.01

Herrera, D. (2010). Husserl y el mundo de la vida. Franciscanum, (LII)153, pp. 247-74. Disponible en: https://dialnet.unirioja.es/descarga/articulo/3703031.pdf

Jaramillo, J. (2018). La literatura como estrategia didáctica para la enseñanza de la historia. Pereira: Universidad Tecnológica de Pereira.

Jurado, F. (2004). Palimpsestos: la literatura en el contexto escolar. En: Teoría, historia, crítica, 6, pp. 269-296

Larrosa, J. (1998) La experiencia de la lectura. Estudios sobre Literatura y Formación. Barcelona: Editorial Laertes

Levy, P. (2007). Cibercultura: la cultura de la sociedad digital. Barcelona: Anthropos

Lineros Quintero, R. (2000). Didáctica de la literatura. España: Contraclave.

Lora, M. E. y Moreno, J. M. (2020). Tensiones en la didáctica de la literatura en educación media: un acercamiento al relato de prácticas de enseñanza desde la literacidad. Medellín: Universidad de Antioquia.

Lyotard, J.-F. (1989). La condición postmoderna. Madrid: Cátedra

Mallart, J. (2000). Didáctica: concepto, objeto y finalidades. En Spulveda, F., Rajadell, N. (Coords.) Didáctica general para psicopedagogos. Madrid: UNED-

Martínez, Z. y Murillo Pineda, R. (2013). Concepciones de la Didáctica de la Literatura en Colombia durante los últimos diez años. Revista Grafía (1),10, pp. 175-194. https://doi.org/10.26564/16926250.394

Ministerio de Educación Nacional. (1998). Lineamientos curriculares del área de la lengua Castellana. Bogotá: MEN.

Ministerio de Educación Nacional. (2015). Derechos Básicos de Aprendizaje (DBA). Bogotá: MEN

Miranda, L.E. (2019). El cine foro como estrategia didáctica en la enseñanza de la literatura latinoamericana en la escuela. Bogotá: Universidad Santo Tomás.

Montes, L.M. (2020). La escuela anestesiada. Entre las políticas educativas colombianas y la educación literaria. Una investigación documental (1996-2016). Bogotá: Universidad Pontificia Javeriana.

Moreno, E.Z., Castro, J., Acevedo, L. F., Acuña, A., Angarita, E. O., Barajas, Y. E., Cubides, M. D., Galvis, J. S., Gómez, G., Gómez, M. F., Gutiérrez, F., Mantilla, C. Mogollón, S. M., Muñoz, V., Otálora, Y., Pineda, A. S., Rodríguez, A., Socha, O. I., Tapias, E., Villamizar, S. Y. (2011). Cómo enseñar literatura en el aula, propuestas creativas para maestros activos. Bucaramanga: Universidad Cooperativa de Colombia.

Paredes, E. A. (1995). La enseñanza-aprendizaje de la literatura en el bachillerato. Perfiles Educativos, (68). https://www.redalyc.org/pdf/132/13206810.pdf

Paternina, D.G. (2017). Estrategias, didáctica para el desarrollo del plan lector en el aula de grado $9^{\circ}$ de bachillerato a través de las tecnologías de la Información y Comunicación. Bogotá: Universidad Internacional de la Rioja.

Piaget, J. (1960). Estudes d'Epistémologie Génetique. Buenos Aires, Argentina: Ed. Emece el libro de arena.

Posada, E. A. (2019). Secuencia didáctica como mediación pedagógica para la promoción de la lectura crítica en estudiantes de grado $8^{\circ}$ de una Institución Educativa del municipio de Manizales - Colombia. Miradas Revista Investigación Universidad Tecnológica de Pereira, pp.103-131. https://doi.org/10.22517/25393812.22021 
Real Academia Española. (2019). Literatura. En Diccionario de la lengua española. Recuperado de https://dle.rae.es/literatura?m=form

Robledo, B. H. (2010). El arte de la mediación. Espacios y estrategias para la promoción de la lectura. Bogotá: Norma.

Rodari, G. (1973). La gramática de la fantasía. Barcelona, España: Ed. Planeta

Rodari, G. (1999). Gramática de la fantasía. Introducción al arte de inventar historias. Bogotá: Panamericana Editorial.

Saavedra, S. (2011). La creación literaria en el ámbito educativo: de la estructura superficial a la construcción narrativa de la realidad. Lenguaje, (37), pp. 395-417. https://doi.org/10.25100/lenguaje.v39i2.4937

Saavedra, S. (2013). Hacia una evaluación formativa, crítica y artística de la creación literaria. Folios, (37), pp. 167-183. https://doi.org/10.17227/01234870.37folios167.183

Saavedra, S. (2017). Formación (Bildung) y creación literaria. "Llegar a ser lo que se es” en diversos mundos posibles. La palabra, (31), pp. 197-210. https://doi.org/10.19053/01218530.n31.2017.7267

Saavedra, S. (2020). La formación (Bildung) literaria basada en la creación de ficción. Folios, (51), pp.3-16. https://doi.org/10.17227/folios.51-8737

Sanabria, L.M. (2018). Transformación del canon literario formativo para contribuir en el desarrollo de la competencia lectora y el deleite literario desde la novela colombiana femenina del siglo XXI. Ibagué: Universidad del Tolima.

Sierra, J.A. (2019). La historieta digital como estrategia virtual para el desarrollo de la competencia narrativa literaria en estudiantes de grado noveno del colegio juana escobar (IED) para la jornada tarde. Bogotá: Universidad EAN

Suaza, A. (2017). Literatura y música: una propuesta en el aula de Humanidades y Lengua Castellana para el fomento de la lectura, la escritura y la oralidad. Bogotá: Universidad Distrital Francisco José de Caldas

Schutz, A. (1973). El problema de la realidad social. Buenos Aires: Amorrortu.

Torres, D. R. (2017). Didáctica Literaria. Enfoque crítico y formador de la lectura recreativa. Colombia: Universidad Militar Nueva Granada.

Trujillo, F. (2018). La didáctica de la literatura en secundaria. En: Amauta, 16(32), pp. 49-68. https://doi.org/10.15648/am.32.2018.4

Vygotsky, L. (1938). Pensamiento y Lenguaje. Ciudad de México: Ed. Paidós. 